\title{
Diálogos intermitentes: relações entre Brasil e América Latina
}

LÚCIA LIPPI OLIVEIRA

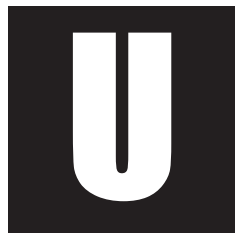

ma das primeiras reflexões a se fazer quando se pensa na América Latina tem a ver com uma dupla questão: Como o Novo Mundo se tornou América e quando esse nome foi apropriado pela sociedade situada ao norte do continente?

A construção do conceito de América a partir da conquista passou por vários e distintos caminhos. $\mathrm{O}$ "outro" americano foi definido enquanto tal, em contraposição à Europa, e foi mesmo ele, aliás, que possibilitou a construção de uma identidade européia. O Novo Continente foi exaltado durante os séculos XVI e XVII por sua natureza e pela presença de um indígena idealizado, mas, no século XVIII, passou a ser visto como uma terra incapaz de se tornar civilizada (O'GORMAN, 1992). Foi só ao final do século XVIII e começo do XIX, com a independência dos Estados Unidos e, mais tarde, das colônias hispânicas e portuguesa, que a idéia de América passou a ter nova dimensão política que envolvia o rompimento dos laços coloniais. E foi esse rompimento com as metrópoles que exigiu um grande esforço de criação de um sentido de unidade.

Os novos países hispano-americanos constituídos após a independência vieram expressar não uma fragmentação mas, sim, uma incapacinadas

* Socióloga, pesquisadora e professora do CPDOC/FGV. 
em prol de uma identidade comum que acabou se apresentando como "americana". A ex-colônia portuguesa, por sua vez, venceu a fragmentação pela centralização monárquica que pretendia ser a continuação da civilização européia nos trópicos. Ser americano no caso brasileiro, é bom lembrar, só vai aparecer como demanda, no Manifesto Republicano de 1870.

Uma segunda pontuação a ser feita tem a ver com o contexto no qual a própria idéia de uma América Latina foi formulada. Isto nos foi relembrado por Richard Morse em seu livro O Espelho de Próspero (publicado em 1982, no México, e em 1988, no Brasil), que discute os conflitos entre as culturas anglo-americana e ibérica. Nesse livro Morse se recusa a estabelecer o contraste entre América Latina e Estados Unidos, e em seu lugar utiliza os conceitos de Ibero-América e Anglo-América, querendo com isto realçar a herança ideológica e institucional das duas nações matrizes. Lembra ele que o termo América Latina provém da França sob Napoleão III, - surgiu após uma expedição militar e científica francesa ao México e apareceu, pela primeira vez, em livro publicado em 1862 - que desejava defender uma suposta unidade de língua, de cultura e de "raça" dos povos latinos. Seu objetivo era reagir ante a expansão americana e facilitar a libertação dos países de colonização espanhola da tutela da mãe pátria ibérica. Tratava-se, portanto, de uma disputa entre os Estados Unidos e a França pelo espólio espanhol do final do século XIX.

A América chamada latina, a partir da segunda metade do século XIX, viveu obcecada pelo futuro, ao mesmo tempo que se mostrava incapaz de lidar com as sociedades já existentes e apresentava dificuldades para encontrar seu espaço na sociedade capitalista em expansão. Diferentes correntes modernizadoras produziram a noção de que, nesta região, não haveria nenhuma história, nenhum passado utilizável para a consolidação das comunidades nacionais. Para se chegar aos patamares das na-

1 Outros dados sobre a origem do conceito de América Latina ver SANTOS, 2004. 
ções avançadas seria preciso, segundo os modernizadores, remover os obstáculos e colocar em seu lugar modelos já prontos e definidos.

A esta corrente modernizadora se contrapôs a corrente chamada arielista - assim chamada a partir da obra do uruguaio José Enrique Rodó, Ariel, publicada em 1900 -, que esteve ocupada com questões de identidade, com a revalorização do passado e da cultura ibérica. Os arielistas criticaram o cientificismo positivista e recuperaram o idealismo e a perspectiva romântica, propugnando por uma aristocracia de espírito e por uma liderança comprometida com o espírito público. Desejavam também combater e vencer o caudilhismo, integrar os fragmentos deixados pelas lutas do século XIX e estimular, pela educação, o sentimento nacional e a recuperação da memória dos heróis nacionais.

A perda pela Espanha dos últimos redutos na América -Cuba e Porto Rico (1898)-, juntamente com a publicação de obras como Ariel, deram margem à produção de uma abordagem ocupada com a identidade iberoamericana que forneceu bases ao pensamento nacionalista e à regeneração das nacionalidades ameaçadas pelo cosmopolitismo. É nesta conjuntura que a atuação norte-americana principalmente, no Caribe, reverte a valorização do modelo norte-americano presente em meados do século XIX nas obras dos argentinos Domingo Faustino Sarmiento e Juan Bautista Alberti.

Correntes modernizadoras e identitárias ${ }^{2}$ fizeram parte do pensamento social latino-americano desde meados do século XIX até os dias de hoje. As questões derivadas da modernização e do arielismo podem ser observadas em seus mais significativos autores e pensadores (AROCENA, 1993, 1996; SANTOS, 2004; PAMPLONA, 1995).

Eduardo Devéz Valdés (1992), em artigo centrado no caso chileno, menciona quatro ondas modernizadoras na América Latina, ao longo des-

2 Sobre a construção de identidade na América Latina, elaboradas a partir de temas recorrentes como: latinidade, mestiçofilia indigenista ou afro-americana, nacionalismo e antiimperialismo.Ver VALDÉS (1997). 
se período. A primeira seria configurada por Sarmiento e Alberti, que apresentaram um projeto modernizante para o continente por volta de 1850. A geração positivista do fim do século XIX até 1910, seria a segunda onda. ${ }^{3}$ Durante e após a Segunda Guerra Mundial, a modernização se expressou no desenvolvimento baseado nas idéias de industrialização e substituição de importações. Por fim, a quarta onda, apresentou-se a partir das ditaduras modernizadoras do continente.

As relações culturais entre o Brasil e os demais países da América do Sul têm sido marcadas por um jogo de construção de identidades e de alteridades que se alternam ao longo do tempo. No fim do século XIX, podemos observar alguns autores que apontam principalmente para as diferenças e para o que seria a superioridade brasileira. A avaliação que os historiadores monarquistas fizeram da América Latina enfatizava as mazelas das Repúblicas da América do Sul e os benefícios do fato de a independência brasileira ter-se realizado com a continuidade do regime monárquico. Podemos citar como exemplo Eduardo Prado em seu livro $A$ ilusão americana, de 1893. A América espanhola, ao adotar o modelo norte-americano por ocasião dos movimentos de independência durante o século XIX, teria renegado suas tradições. Se os Estados Unidos são acusados por Prado nesse livro de ter uma política externa invasora, tirânica, arrogante e oportunista, as repúblicas da América espanhola são, por outro lado, identificadas com o militarismo e o caudilhismo. Para Prado, foi o regime imperial no Brasil que manteve sob controle o caudilhismo que sufocava os outros países da América do Sul. 
No final do século XIX e início do XX, ou seja, na segunda onda modernizadora, vieram da Europa não só os imigrantes mas também as idéias que postulavam a inferioridade dos mestiços em relação às raças puras, e dos negros ante os brancos. Parcelas da intelectualidade brasileira, sob influência destas doutrinas, passaram a valorizar o lado biológico (racial) das relações sociais. O Brasil passou a ser visto como uma sociedade atrasada e doente, já que era formada por um grande contingente de raças consideradas inferiores e por uma imensa população miscigenada, ambas identificadas como obstáculos ao progresso e à harmonia social. A grande onda migratória de população originária principalmente da Europa pretendeu não resolver, mas minimizar esta condição através da chamada "teoria do branqueamento". O Brasil, vale lembrar, é uma nação em que tanto as elites quanto o povo vieram de fora - as elites, do sul da Europa e o povo, predominantemente da África. Os índios, antigos habitantes da terra, quase desapareceram, ainda que estejam presentes na herança genética, o que nos diferencia dos países andinos e do México, onde a presença indígena é visível a olho nu. Somos um caso do que Darcy Ribeiro chamou de "sociedades transplantadas".

No século XX, já sob a República, a diferença de regime não mais existia como elemento de diferenciação entre o Brasil e as repúblicas latino-americanas. Na primeira década do século XX, vivemos um processo de modernização que procurou construir uma imagem do país, condizente com o imaginário europeu civilizado. No Rio de Janeiro, então capital federal, as reformas urbanas desejavam transformar a cidade em uma Paris tropical. O progresso e a riqueza da República Argentina pareciam seduzir e ameaçar os nacionais, e Buenos Aires passou a ser considerada a cidade mais européia do continente.

As relações intermitentes entre diversos países do continente podem também ser acompanhadas se observarmos a presença de alguns intelectuais e diplomatas que estabeleceram conexões relevantes entre suas eli- 
tes. Em 1922, por ocasião do Centenário da Independência do Brasil, José Vasconcelos, o mais importante intelectual mexicano do seu tempo, visitou o Brasil e reforçou a idéia de uma raça ibérica superior (TENORIO, 1994). Ainda sobre as relações México-Brasil, cabe mencionar a presença de Alfonso Reyes, que foi embaixador do México no Brasil, entre 1930 e 1936, e antes estivera em missão diplomática na Argentina (1927-1930), na França (19241927) e na Espanha (1920-1924). (ELLISON, 2002). Esse intelectual mexicano manteve importantes relações com a intelectualidade carioca e representava a presença da cultura espanhola por seus vínculos com Ortega y Gasset e a Revista do Ocidente, e com Unamuno. ${ }^{4}$ No mesmo período, seu equivalente brasileiro pode ser considerado Ronald de Carvalho, que, como herdeiro da presença de intelectuais no Itamaraty, buscava construir um intercâmbio cultural entre Brasil e México (BOTELHO, 2002).

A Revolução Mexicana de 1910 e, mais tarde, a Revolução Cubana de 1959, foram eventos políticos e culturais que marcaram o imaginário dos intelectuais latino-americanos e brasileiros durante o século XX. No entanto, as relações intelectuais e culturais entre países da América Latina ainda precisam ser mais e melhor compreendidas. ${ }^{5} \mathrm{O}$ avanço de pesquisas sobre a América Latina, no Brasil, tem privilegiado a história política e cultural e se expressa em números especiais de revistas que trazem dossiês sobre o tema. ${ }^{6}$ Os cursos de pós-graduação em História e em Ciências Sociais das universidades do sul do país são os que apresentam maior ênfase nesta temática.

O que importa mencionar aqui tem a ver com o período chamado de terceira onda de modernização, aquele que se desdobra da Segunda Guerra Mundial.

\footnotetext{
4 A importância do pensamento espanhol e, em especial, Ortega y Gasset, no Brasil, vem sendo trabalhada por BASTOS, 2003a, 2003b.

5 Contamos nos dias de hoje com a tradução da obra organizada por Leslie Bethell, História da América Latina (1997), que apresenta importantes artigos históricos e abre perspectivas para futuros estudos.

6 A revista História, São Paulo, Unesp, vol. 22, n. 2, 2003, pode ser um bom exemplo. Assim como a Diálogos, Universidade Estadual de Maringá, vol. 1, n. 1, 1997.
} 
Foi nos anos 50 que, pela primeira vez na história do Brasil, o mundo urbano sobrepujou o rural em termos de imaginário da sociedade brasileira. Foi consagrado, nessa época, um discurso no qual o mundo rural era identificado como atrasado, velho, passado, enquanto o mundo urbano seria visto como adiantado, novo, moderno. Os anos do governo Juscelino Kubitschek no Brasil foram marcados pela idéia de incorporação do que era novo e moderno: o desenvolvimento, as estradas, as hidroelétricas, a arquitetura moderna, a música, e pela idéia de que era possível recuperar o tempo perdido, daí o slogan "50 anos em 5". Estávamos de fato em um tempo cultural acelerado, marcado pelo espírito do "novo" e pela vontade de mudança. Tudo é novo: Novacap, cinema novo, bossa nova. (VELOSO \& MADEIRA, 1999).

Foi nesta década que foi construída uma nova categoria para pensar o Brasil e a América Latina. Não se falaria mais em "atraso" mas em "subdesenvolvimento". Este conceito foi elaborado pelos pensadores que participavam da Comissão Econômica para a América Latina (Cepal), órgão das Nações Unidas, criado em 1948, com sede em Santiago do Chile. As idéias da Cepal - a industrialização pela substituição de importações; a deterioração dos termos de troca; a necessidade de proteção do mercado interno; o papel fundamental do Estado no processo de desenvolvimento - tiveram nos economistas Raul Prebish e Celso Furtado seus mais importantes formuladores. Mas esta nova matriz, elaborada a partir da análise econômica, irá transbordar para outros campos do conhecimento.

O grande tema passou a ser a Mudança Social. A sociologia voltou-se para a pesquisa sobre os condicionantes sociais do desenvolvimento; as resistências à mudança; a dicotomia arcaico versus moderno. Explicar como a sociedade se desenvolve passou então a ser questão central das ciências sociais da época - como definir claramente a oposição entre tradição e modernidade; como encontrar os substitutos funcionais da ética protes- 
tante para localizar as modernizações que teriam condições de dar certo; como entender as diferentes etapas desse processo. As mazelas sociais personalismo, familismo, patrimonialismo - explicariam, por sua prémodernidade, as dificuldades e diferenças nas etapas do desenvolvimento. Tudo isso valeu para o Brasil e para a América Latina e conformou o pensamento e as propostas dos intelectuais e dos cientistas sociais.

O projeto nacional-desenvolvimentista que se desenvolveu à época, no Brasil, teve como primeiro espaço de sua formulação o Instituto Brasileiro de Estudos Sociais e Políticos (IBESP), criado em 1952. Suas propostas e estudos foram divulgados nos Cadernos do Nosso Tempo, publicados entre 1953 e 1956. Lá se formulou uma perspectiva nacionalista ocupada com o Terceiro Mundo, ou seja, postulou-se uma terceira posição entre os dois blocos em que se dividia o mundo durante a Guerra Fria.

A seguir, em 1954, foi criado o Instituto Superior de Estudos Brasileiros (ISEB) que assumiu a mesma perspectiva da Cepal, já que a economia oferecia uma explicação estrutural para os problemas brasileiros. Mas acrescentava-se agora a necessidade de uma ideologia do desenvolvimento, sem a qual não haveria processo de mudança. Nessa ideologia do desenvolvimento, o Estado era visto como agente da modernização e passava a ser entendido também como agente da democratização, pela incorporação de parcelas do povo (integradas aos sindicatos) através da industrialização.

Subjacente a essa ideologia do desenvolvimento havia uma filosofia da história - concepção de fases, de etapas do desenvolvimento histórico - e o Brasil era visto como dividido em dois campos: o lado moderno, dinâmico, produtivo, que se contrapunha ao tradicional, estático, parasitário; ou nação versus antinação. E o nacionalismo de então era pensado como a ideologia capaz de vencer as forças do atraso e a exploração das massas. Ou seja, essas formulações serviam para explicar a realidade mas, acima de tudo, serviam para convencer grupos e classes a lutar para alcançar uma nova realidade social. 
A partir do ISEB, e dentro dele, no início da década de 1960, acirraram-se as lutas ideológicas entre marxistas, liberais, conservadores, reacionários, pela hegemonia do processo. Para isebianos "à direita", o capitalismo se constituía na modalidade suprema da ordem civilizada, para os isebianos "à esquerda", o socialismo somente poderia raiar no horizonte, depois que o capitalismo se consolidasse na periferia.

A transição entre sociedade tradicional e moderna, rural e urbanoindustrial ocupou as atenções de diferentes intelectuais, que sentiram necessidade não só de explicar os males do Brasil, mas também de atuar na vida política para vencê-los. Nesse aspecto, o ISEB negou a tese da neutralidade da ciência no campo das Ciências Sociais, fez a defesa do engajamento e da militância, não aceitou a separação entre ciência e política (BOBBIO, 1997).

A formação de uma elite dirigente, capaz de implementar o projeto desenvolvimentista para toda a América Latina, comprometida com os interesses gerais da nação e atuando acima dos interesses dos diferentes grupos, marcou o período dos anos 1950 em diante. Foram feitos esforços para formar uma burocracia/tecnocracia capaz de levar adiante as idéias de desenvolvimento, de promover a modernização do continente, e isso permitiu a emergência de um conjunto de questões e temas, que tornou possível uma conversa entre profissionais e intelectuais de vários países latino-americanos. É preciso lembrar que seu contraponto - uma intelligenztia revolucionária - também se fez presente em todo o continenta, ainda que, em cada país, ela tivesse contorno distinto.

O processo de modernização em curso possibilitou também o desenvolvimento da sociologia como disciplina científica. O modelo de excelência acadêmica era baseado em valores universalistas que privilegiavam o mérito, julgamento segundo padrões internos, orientação para a pesquisa, alto senso de autonomia e profissionalismo disciplinar. Tudo isto 
configurava os padrões que as universidades norte-americanas exportavam para o mundo e difundiam pela socialização de estudantes de pós-graduação em suas universidades.

É preciso lembrar que um primeiro momento da presença de um ethos acadêmico de inspiração norte-americana já se fizera presente no Brasil, na Escola Livre de Sociologia e Política, criada em São Paulo em 1933, e onde Donald Pierson passara a divulgar os padrões do trabalho sociológico da Universidade de Chicago. Um segundo momento aconteceu nos anos 1960 e teve a ver com as mudanças políticas que levaram muitos latino-americanos a se exilar nos Estados Unidos e lá estudar a América Latina. Foi a partir do interesse dos americanos em estudar a América Latina (após a Revolução Cubana) aliado à presença dos latinoamericanos nos Estados Unidos que se criou, em 1966, a Latin American Studies Association (LASA) (MICELI, 1990).

A história, a trajetória, as principais figuras das Ciências Sociais já foram objeto de diversas pesquisas reunidas nos dois volumes editados por Sérgio Miceli (1988 e 1995), as quais tiveram como eixo central o estudo da chamada "escola sociológica paulista". A institucionalização das Ciências Sociais foi analisada, tomando como eixo predominante a distinção vigente nos universos culturais, políticos e universitários entre São Paulo e Rio de Janeiro. Outro texto que analisou o tema foi o de Luiz Werneck Vianna (1997), que aborda duas matrizes que teriam orientado a perspectiva de atuação dos cientistas sociais. Uma delas é a "concepção mertoniana", baseada na idéia de uma comunidade científica moderna e democrática, que produziu pesquisas visando entender a transição de uma sociedade na qual predominava o patrimonialismo, para uma ordem competitiva. A outra matriz é uma "intelligentzia mannheiniana", desejosa de compreender a situação histórico-social e fornecer os meios para intervir na sociedade. Esta última teve nos isebianos seu caso exemplar como 
intelligentzia modernizante que privilegiava o papel transformador do Estado. Os mertonianos, exemplificados na figura de Florestan Fernandes e na sociologia paulista, também desejavam apressar a mudança, apontar os obstáculos a serem enfrentados e se centravam na reforma da sociedade civil, principalmente pela educação e reforma do ensino. Assim, segundo Werneck Vianna, "apesar das divergências, eles convergem ao inscrever a disciplina na vida pública em torno de uma agenda de reformas sociais" (p. 198). Foram ambas as matrizes portadoras de uma ciência que diagnostica os problemas e prevê soluções para o desenvolvimento e para o statebuilding, ainda que os diagnósticos e as soluções fossem diferentes.

As questões derivadas do contexto político ideológico dos anos 1950 e 1960, assim como as presenças francesa e norte-americana na formação e institucionalização das ciências sociais no Brasil, como já mencionamos, estão destacadas nos trabalhos dedicados à história das Ciências Sociais no Brasil.

A presença de organismos internacionais na conformação de uma comunidade acadêmica chamada "científica" ou "mertoniana" passou a ganhar maior destaque e visibilidade, valendo citar a pesquisa de Hélgio Trindade, que começa a publicar seus resultados. O quadro de criação de instituições de Ciências Sociais na Argentina, no Brasil e no México entre 1930 e 1970 apresentado pelo autor (TRINDADE, 2004, p. 156-157), mostra como a institucionalização foi "autônoma" em cada um dos países e, ao mesmo tempo, "convergente".

A presença da Unesco, por exemplo, como agência de fomento a diversas instituições vem merecendo atenção nos trabalhos de Marcos Chor Maio (1997; 1999; 2004). A atuação da Unesco, lembra-nos o autor, desde sua origem em 1945 era movida pelo princípio de assegurar ciência, educação e cultura para todos, irradiar a ciência e o conhecimento, do centro para a periferia. Sua proposta de atuação esteve guiada por um sentido transnacional, de combate ao nacionalismo nazi-fascista, e por 
princípios morais e éticos, já que a associação entre ciência e Estado em tempos de guerra havia gerado efeitos perversos. Dois projetos iniciais da Unesco tiveram a ver com o Brasil, a pesquisa da riqueza biológica e ecológica dos biomas de florestas úmidas tropicais e a luta contra o racismo (MAIO, 2004).

Além do estudo das relações raciais no Brasil (MAIO, 1999), a Unesco financiou projetos no Centro Brasileiro de Pesquisas Educacionais (CBPE), criado em 1955, por Anísio Teixeira. ${ }^{7}$ No CBPE tiveram presença diversos técnicos da Unesco como Charles Wagley, Bertram Hutchinson e Oto Kleinberg, além de pesquisadores brasileiros como Josildeth Consorte, Luís de Aguiar Costa Pinto, Waldomiro Bazzanella e Darcy Ribeiro, entre outros.

Outro centro criado no Rio de Janeiro em 1957 com ajuda da Unesco foi o Centro Latino Americano de Pesquisas em Ciências Sociais (CLAPCS). No CLAPCS, assim como no CBPE, desejava-se que as Ciências Sociais pudessem resultar em uma aplicação prática, tendo em vista as transformações que o Brasil e a América Latina estavam vivenciando. As Ciências Sociais deveriam ser capazes de formar especialistas e realizar pesquisas que pudessem ajudar a enfrentar os graves problemas concretos de natureza social, econômica e política decorrentes da passagem do subdesenvolvimento ao desenvolvimento através do processo de industrialização do continente. Como agência internacional de fomento, a Unesco desejava impulsionar não só estudos e levantamentos, mas também centros de documentação e de informação sobre a região. ${ }^{8}$

Retomando alguns aspectos que já mencionei em trabalho anterior (OLIVEIRA, 1995) podemos apontar como as ciências sociais, em particular a sociologia, esteve conectada à problemática de diferentes países que

\footnotetext{
7 Este Centro se beneficiou de experiência anterior de convênio que Anísio Teixeira desenvolvera entre o governo da Bahia e a Universidade de Columbia.

8 Uma das figuras relevantes nessa conexão entre agências internacionais e centros latino-americanos de pesquisa é o sociólogo Luiz de Aguiar Costa Pinto, primeiro diretor do CLAPCS (MAIO e VILAS BOAS, 1999).
} 
compõem a América Latina, no início dos anos 60, através das páginas da revista do CLAPCS, América Latina. A observação de sua revista pode indicar que o CLAPCS inaugurou uma dimensão nova, no sentido de escopo espacial de sua temática. Foi ali que tivemos um momento de "integração" dos estudos sobre América Latina.

O CLAPCS cria, em 1958, um Boletim que, em 1962, tornou-se a revista trimestral América Latina. Além de publicar artigos, a América Latina apresentava informes e noticiários sobre congressos, reuniões, cursos, atividades do CLAPCS, informes sobre livros e revistas, resenhas bibliográficas, balanços sobre a situação da documentação. Trazia ainda outra seção dedicada à apresentação de projetos de pesquisa em andamento. Assim, além de ser uma revista que publicava artigos acadêmicos, era também um boletim informativo e bibliográfico. A valorização da documentação, da organização de bibliotecas e de intercâmbio de informação, como já mencionamos, faz parte do receituário das agências internacionais de fomento à pesquisa.

No Boletim e na revista América Latina, entre 1959 e 1976, temos 251 artigos acadêmicos publicados, sendo que 45 deles têm como tema a América Latina, e 11 comparando dois ou mais países. Além disso, são 10 artigos sobre o Brasil; 9 sobre o Chile, Costa Rica, Peru; 8 sobre a Argentina; 7 sobre o México e Uruguai; 5 sobre Haiti e Venezuela.

No universo de colaboradores (200) estão, além de Wright Mills, Alain Touraine, Roger Bastide, Andrew Pearse e Bertram Hutchison, alguns dos sociólogos latino-americanos mais conhecidos tais como Gino Germani, Rodolfo Stavenhagem, Aldo Solari, Jean Casimir, Jorge Graciarema, Torcuato Di Tella, Júlio Cotler, Pablo González Casanova, Eliseo Verón. Entre os brasileiros, tiveram artigos publicados na revista, Aparecida Joly Gouveia, Carlos Alberto Medina, Gláucio A. D. Soares, Manuel Diégues Jr., Fábio Wanderley 
Reis e Sugiyama lutaka.

A temática maior da revista foi mesmo a Sociologia do Desenvolvimento, fortemente marcada pelas orientações cepalinas: a noção de sociedade dual (arcaico versus moderno) e a análise dos indicadores deste processo - grau de urbanização e industrialização; índices de mobilidade social; de analfabetismo; integração da população na economia formal, além de aspectos comportamentais tratados como mudança de mentalidade.

A necessidade de estabelecer uma metodologia comum tendo em vista a escala continental das pesquisas também é ressaltada em muitos artigos. Esperava-se que, com esses estudos comparativos, seria possível alcançar conhecimentos mais globalizantes. Países, regiões ou cidades da América Latina são apresentados por dados estatísticos censitários ou dados de surveys realizados pelos autores/pesquisadores. Esses dados são trabalhados e dão origem a análises comparativas no tempo (o mesmo país em momentos distintos), ou no espaço (dois ou mais países da América Latina). A análise sociológica, na maioria dos artigos da América Latina, aparece dissociada dos contextos históricos das cidades e dos países onde se aplica a pesquisa.

A suposição era que o processo de modernização em curso faria desaparecer não só o subdesenvolvimento, mas também os desequilíbrios regionais e as injustiças sociais. Eliseo Verón, em artigo crítico em relação à Sociologia do desenvolvimento (América Latina, n. 4, 1968), faz um balanço das pesquisas em curso na América Latina, apontando três tipos: a) aquelas que reuniam dados sobre a estrutura social (estratificação, mobilidade, urbanização e industrialização; b) aquelas centradas em aspectos particulares da estrutura social e que permitiam avaliar os recursos disponíveis para o desenvolvimento (educação primária, secundária e universitária, capacitação profissional, incorporação de migrantes à vida urbana, entre outros; c) pesquisa sobre atitudes e opiniões. Para Verón, entretanto, essa sociologia, ela- 
borada sobretudo nos Estados Unidos, envolvida na produção de índices múltiplos para classificar países como "em vias de desenvolvimento", não estaria sendo capaz de ver a realidade, já que os países estariam, na verdade, "en vias de empobrecimiento y sometimento militar".

O CLAPCS, em sua revista, publicou o que era considerado como científico em termos de uma Sociologia produzida na América Latina. Foi pioneira em sua abrangência, ao tomar como objeto de estudo a América Latina.

O CLAPCS foi um importante centro de divulgação da melhor Sociologia e, entretanto, não desenvolveu maiores laços com as precárias instituições de ensino existentes no Rio de Janeiro e não formou quadros que dessem continuidade ao que ali se fez. Houve pouco tempo de vida institucional, já que o Centro começou a entrar em descenso a partir da ditadura militar no Brasil.

Escrevi isto no início dos anos 1990 (publicado em 1995), entretanto, ao fazer uma entrevista, em 2004, com a socióloga Lícia Valladares ouvi o seguinte depoimento:

A pessoa fundamental em meus estudos sobre favela chama-se Carlos Alberto Medina [sociólogo que trabalhava no CLAPCS]. Porque, quando eu estava na PUC, fui trabalhar no Centro Latino-Americano de Pesquisas em Ciências Sociais (CLAPCS). O Manuel Diegues Júnior, nosso professor na PUC, era o diretor do CLAPCS e levou a Madalena Diégues, a mim e a Alice Rangel, depois Alice Rangel de Paiva Abreu, para trabalhar do Centro de Documentação do CLAPCS. Nossa função na época era fazer resumo de artigos, - creio que daí vem o meu interesse por montar bibliografias e que mais tarde dará origem ao Urbandata... IUm dos mais importantes banco de dados bibliográficos sobre urbanismo]. Foi nessa época, em 1966, que eu comecei a trabalhar no Centro Latino-Americana, que era o centro de pesquisa mais importante do Rio de Janeiro. Eu me 
lembro que por lá passaram o Alan Touraine, o Fernando Henrique Cardoso, o Anthony Leeds, o Lucien Parisse, o Luís Antonio Machado... E eu, que estava na faculdade, tinha um interesse muito grande em me juntar àquelas pessoas e a começar a fazer pesquisa. Um dia o Medina virou-se para mim e para a Alice Rangel e nos convidou a trabalhar no Centro de Estatística Religiosa e Investigação Social (Ceris), que era um centro de pesquisa da Igreja Católica.

Ou seja, mesmo que minha interpretação anterior sobre o CLAPCS, na qual tratava o Centro como "enclave", seja plausível, novos dados e depoimentos podem vir a indicar a existência de vestígios do CLAPCS na trajetória de outros sociólogos, ainda que a presença dos latino-americanos no Centro não tenha levado a uma maior integração com os sociólogos brasileiros.

O CLAPCS, criado em 1957 no Brasil e a FLACSO, criada em 1958 no Chile, como pólo formador de pós-graduados selecionados em toda a América Latina, podem ter representado espaços para circulação de uma elite de sociólogos mertonianos que, independentemente da perspectiva de atuação e de sua qualificação, sofreram as conseqüências da instabilidade política no Brasil (1964), na Argentina (1969) e no Chile (1974).

Muita coisa mudou desde então para os países da América Latina. O fim das ditaduras militares no cone sul; a inserção em uma economia mais globalizada, carimbada com o nome de neoliberal; a vigência de estruturas políticas razoavelmente democráticas; a formação de blocos, no caso específico, o Mercosul. E, no campo das ciências sociais, o crescimento da pós-graduação em escala notável.

Esta história dos anos 60 pode ajudar-nos a pensar os tempos atuais marcados pelo esforço de construção de um mercado comum de bens econômicos e de bens simbólicos entre os países da América Latina. Há que se aproveitar a ocasião para restabelecer o caminho do diálogo cultural entre os aparentados da família ibérica. 


\section{Referências}

ALONSO, Ângela. Idéias em movimento. A geração 1870 na crise do Brasil-Império. São Paulo: Paz e Terra, 2002.

AROCENA, Felipe. Muerte y resurrección de Facundo Quiroga. Historia cultural de lo que ha significado "ser moderno" para los latinoamericanos. Montevideo: Ediciones Trilce, 1996.

BASTOS, Élide Rugai. A revista Cultura Política e a influência de Ortega y Gasset. In BASTOS, Élide Rugai; RIDENTE, Marcelo; ROLLAND, Denis (Orgs.). Intelectuais: sociedade e política. São Paulo: Cortez, 2003 a. p. 146-171.

BASTOS, Élide Rugai. Gilberto Freyre e o pensamento hispânico. Entre Dom Quixote e Alonso El Bueno. Bauru/SP: EDUSC, 2003 b.

BETHELL, Leslie (org.). História da América Latina. São Paulo: Edusp; Brasília: Fundação Alexandre Gusmão, 1997.

BOBBIO, Norberto. Os intelectuais e o poder. São Paulo: Unesp, 1997.

BOTELHO, André. Um ceticismo interessado. Ronald de Carvalho e sua obra dos anos 20. 2002. Tese (Doutorado em Ciências Sociais). Departamento de Ciências Sociais, UNICAMP,Campinas.

DEVÉZ VALDÉS, Eduardo. Del Ariel de Rodó a la Cepal. Buenos Aires: Biblos, 2000.

DEVÉZ VALDÉS, Eduardo. O pensamento nacionalista na América Latina e a reivindicação da identidade econômica (1920-1940). Estudos Históricos, Rio de Janeiro, vol. 10, n. 20, p. 321-343. 1997.

DEVÉZ VALDÉS, Eduardo. Modernização e identidade: as idéias na América Latina. Estudos Históricos, Rio de Janeiro, vol. 5, n. 9, p. 75-83. 1992.

ELLISON, Fred P. Alfonso Reis e o Brasil; um mexicano entre os cariocas. Rio de Janeiro: Topbooks, 2002.

MAIO, Marcos Chor. A história do projeto UNESCO; estudos raciais e Ciências Sociais no Brasil. 1997. Tese (Doutorado em sociologia). Instituto Universitário de Pesquisas do Rio de Janeiro, UCAM, Rio de Janeiro. 
MAIO, Marcos Chor. Demandas globais, respostas locais: a experiência da Unesco na periferia no pós-guerra (1946-1952). In: MAIO, Marcos Chor (org.). Ciência, política e relações internacionais; ensaios sobre Paulo Carneiro. Rio de Janeiro: Fiocruz/Unesco, 2004, p. 145-168.

MAIO, Marcos Chor e VILAS BOAS, Gláucia (orgs.). Idéias de Modernidade e Sociologia no Brasil. Porto Alegre: UFRGS,1999.

MICELI, Sérgio (org.). História das Ciências Sociais no Brasil. Volume 1. São Paulo: Vértice, IDESP/Finep, 1989.

MICELI, Sérgio. A desilusão americana; relações acadêmicas entre o Brasil e os Estados Unidos. São Paulo: Sumaré, 1990.

MICELI, Sérgio. História das Ciências Sociais no Brasil. Volume 2, São Paulo: Sumaré/Fapesp, 1995.

O'GORMAN, Edmundo. A invenção da América: reflexões a respeito da estrutura histórica do Novo Mundo e do seu devir. São Paulo: Unesp, 1992.

OLIVEIRA, Lucia Lippi. A redescoberta do Brasil nos anos 50: entre o projeto político e o rigor acadêmico. In: MADEIRA, Angélico e VELOSO, Mariza (Orgs.). Descobertas do Brasil. Brasília: UnB, 2001. p. 139-161.

OLIVEIRA, Lucia Lippi. As Ciências Sociais no Rio de Janeiro. In: MICELI, Sérgio (org.). História das Ciências Sociais no Brasil. Volume 2. São Paulo: Sumaré/ Fapesp, 1995. p.235-307.

PAMPLONA, Marco Antonio. Uma perspectiva 'arielista' entre los hombres públicos brasileños de fin de siglo: Estados Unidos en los escritos de Joaquim Nabuco e Oliveira Lima. In: Estados Unidos desde América Latina: sociedad, política y cultura. Ciudad de México: CIDE/Colégio de México, 1995. p.183-196.

SANTOS, Fábio Muruci dos. Os homens se entendem em Babel: mito e história da América em Oliveira Lima, José Enrique Rodó e José Marti. 2004. Tese (Doutorado em História). Programa de Pós-graduação em História Social, UFRJ, Rio de Janeiro.

SANTOS, Luís Cláudio Villafañe. As várias Américas: visões do século XIX. Estudos de História, Franca, v. 10, n. 1, p. 11-28. 2003. 
SANTOS, Luís Cláudio Villafañe. O Brasil entre a América e a Europa; o Império e o interamericanismo. São Paulo: Unesp, 2004.

TENORIO, Mauricio. Um Cuauhtémoc carioca: comemorando o Centenário da Independência no Brasil e a raça cósmica. Estudos Históricos, Rio de Janeiro, vol. 7, n. 14, p. 123-148. 1994.

TRINDADE, Hélgio. Institucionalização e internacionalização das Ciências Sociais na América Latina em questão. In: ALMEIDA, Ana Maria F. et alii (orgs.). Circulação internacional e formação intelectual das elites brasileiras. São Paulo: Unicamp, 2004, p. 144-167.

VALLADARES, Lícia. Depoimento. CPDOC. 26 de janeiro de 2004.

VELOSO, Marisa \& MADEIRA, Angélica. Leituras brasileiras: itinerários no pensamento social e na literatura. São Paulo: Paz e Terra, 1999.

VIANNA, Luiz Werneck. A institucionalização das Ciências Sociais e a reforma social: do pensamento social à agenda americana de pesquisa. In: VIANNA, Luiz Werneck A revolução passiva; Iberismo e americanismo no Brasil. Rio de Janeiro: Revan/IUPERJ, 1997.

Recebido: 28/02/2004

Aceite final: 18/04/2005 


\section{Resumo}

A América chamada latina viveu, desde a segunda metade do século XIX, obcecada pelo futuro e com dificuldades para consolidar suas comunidades nacionais. Diferentes correntes modernizadoras, entre elas o cientificismo, se defrontaram-se com correntes nacionalistas, preocupadas com a identidade, com o passado representado pelas culturas indígena e ibérica. É nesse quadro histórico-cultural que são mencionadas as relações de identidade e de diferenciação entre o Brasil e demais países da América Latina. O artigo vai destacar a sociologia dos anos 1950 e 1960 como desdobramentos da matriz da Cepal, e a constituição de duas variantes do fazer sociológico: a concepção mertoniana e a mannheiniana. Por fim, apresenta o CLAPCS e a Revista América Latina, atrelando-os à FLACSO, como espaços de atuação e circulação de uma elite de sociólogos mertonianos.

Palavras-chave: América Latina, modernização, sociologia mertoniana na América Latina, CLAPCS, Revista América Latina. 


\section{Intermittent dialogues: relations between Brazil and Latin America}

\section{Lúcia Lippi Oliveira}

The America we call Latin has lived under an obsession with the future and facing a hard time to consolidate its national communities since the second half of the $19^{\text {th }}$ century. Distinct modernizing thoughts, including scientism, faced nationalist ones concerned about identity, with the past being represented by Indian and Iberian cultures. It is within this historical-cultural framework that relations of identity and differentiation between Brazil and the other countries in Latin America are approached. The article will focus on 1950s and 1960s sociology as a development of the CEPAL matrix, and the constitution of two variants of sociological making: the Mertonian and the Mannheimian Conceptions. Finally, CLAPCS and the América Latina Magazine are presented, relating to FLACSO as a space for action and circulation of an elite of Mertonian sociologists.

Key words: Latin America; modernization; Mertonian sociology in Latin America; CLAPCS; América Latina magazine. 